\title{
RESEARCH
}

Open Access

\section{Prediction of Alzheimer's disease biomarker status defined by the 'ATN framework' among cognitively healthy individuals: results from the EPAD longitudinal cohort study}

Catherine M. Calvin ${ }^{1}$, Casper de Boer ${ }^{2}$, Vanessa Raymont ${ }^{1}$, John Gallacher ${ }^{1}$, Ivan Koychev ${ }^{1 *}$ and The European Prevention of Alzheimer's Dementia (EPAD) Consortium

\begin{abstract}
Background: The Amyloid/Tau/Neurodegeneration (ATN) framework has been proposed as a means of evidencing the biological state of Alzheimer's disease (AD). Predicting ATN status in pre-dementia individuals therefore provides an important opportunity for targeted recruitment into AD interventional studies. We investigated the extent to which ATN-defined biomarker status can be predicted by known AD risk factors as well as vascular-related composite risk scores.

Methods: One thousand ten cognitively healthy older adults were allocated to one of five ATN-defined biomarker categories. Multinomial logistic regression tested risk factors including age, sex, education, APOE4, family history of dementia, cognitive function, vascular risk indices (high systolic blood pressure, body mass index (BMI), high cholesterol, physical inactivity, ever smoked, blood pressure medication, diabetes, prior cardiovascular disease, atrial fibrillation and white matter lesion (WML) volume), and three vascular-related composite scores, to predict five ATN subgroups; ROC curve models estimated their added value in predicting pathology.

Results: Age, APOE4, family history, BMI, MMSE and white matter lesions (WML) volume differed between ATN biomarker groups. Prediction of Alzheimer's disease pathology (versus normal AD biomarkers) improved by $7 \%$ after adding family history, BMI, MMSE and WML to a ROC curve that included age, sex and APOE4. Risk composite scores did not add value.
\end{abstract}

Conclusions: ATN-defined Alzheimer's disease biomarker status prediction among cognitively healthy individuals is possible through a combination of constitutional and cardiovascular risk factors but established dementia composite risk scores do not appear to add value in this context.

Keywords: ATN framework, Risk scores, White matter lesions volume

\footnotetext{
* Correspondence: ivan.koychev@psych.ox.ac.uk

${ }^{1}$ Department of Psychiatry, University of Oxford, Warneford Hospital, Oxford OX3 7JX, UK

Full list of author information is available at the end of the article
}

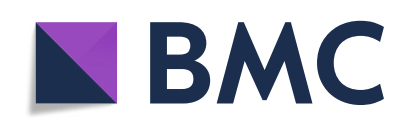

(- The Author(s). 2020 Open Access This article is licensed under a Creative Commons Attribution 4.0 International License, which permits use, sharing, adaptation, distribution and reproduction in any medium or format, as long as you give appropriate credit to the original author(s) and the source, provide a link to the Creative Commons licence, and indicate if changes were made. The images or other third party material in this article are included in the article's Creative Commons licence, unless indicated otherwise in a credit line to the material. If material is not included in the article's Creative Commons licence and your intended use is not permitted by statutory regulation or exceeds the permitted use, you will need to obtain permission directly from the copyright holder. To view a copy of this licence, visit http://creativecommons.org/licenses/by/4.0/. The Creative Commons Public Domain Dedication waiver (http://creativecommons.org/publicdomain/zero/1.0/) applies to the data made available in this article, unless otherwise stated in a credit line to the data. 


\section{Background}

The recognition that Alzheimer's disease (AD) runs a prolonged preclinical course has led to a shift in interventional trials towards its pre-syndromal stages. The Amyloid/Tau/Neurodegeneration (ATN) framework [17] was proposed as means of evidencing the biological state of $\mathrm{AD}$, independent of clinical manifestation. Predicting ATN status through known risk factors and derived scores may provide an important opportunity for aiding preclinical diagnosis and targeted recruitment into AD interventional studies.

Older age and the apolipoprotein e4 (APOE4) genotype are the leading constitutional risk factors for $\mathrm{AD}$, yet modifiable vascular-related risk factors are associated with additional late-life risk of $\mathrm{AD}[24,30,37$, 43], dementia risk [1, 12, 14, 34, 38, 41, 47] and AD pathology biomarkers in preclinical older-age individuals [31, 39, 42]. Despite continuous measures of vascular risk factors relating to ATN biomarkers, little is known about how composite risk scores for dementia relate to ATN-defined biomarker groups among cognitively healthy individuals. Such validation would support the utility of a single vascular risk score for screening high-risk individuals into disease-modifying intervention studies. However, there is no clear consensus about the optimal dementia risk score, and alternative ones have been validated according to different population samples. For example, the Cardiovascular Risk Factors, Aging and Dementia (CAIDE) risk score was originally validated by its prediction of incident dementia 20 years later [25]; the Framingham general cardiovascular score showed an association with 10-year cognitive decline [21]; and the Framingham stroke score showed significant association with contemporaneous cognitive function [9]. A recent study in middle-aged individuals compared them in relation to cognitive decline over 10 years [20] finding that all three predicted 10-year cognitive decline, with Framingham risk scores showing greater strength of association relative to CAIDE.

\section{Methods}

\section{Study design and aims}

Here we tested the predictive utility of validated composite risk scores in their association with ATNdefined biomarker group status in a cognitively healthy ageing sample drawn from the European Prevention of Alzheimer's Dementia longitudinal cohort study (EPAD LCS). Our main aim was to investigate independent risk factors for $\mathrm{AD}$ and vascular-related composite risk scores, in relation to prediction of ATN pathology.

\section{Study setting}

The sample is drawn from 1500 adult participants aged over 50 years from EPAD LCS (dataset V1500.0) [40, 46]. It recruited participants across 21 European sites across the full range of anticipated probability for $\mathrm{AD}$ development [46]. Baseline measurements included brain imaging, fluid biomarkers, cognitive performance, medical history, functional capability, physical examination and neuropsychiatric assessment. For the purposes of this preclinical $\mathrm{AD}$ analysis, we excluded participants with known diagnosis of dementia or Mild Cognitive Impairment (MCI) or Clinical Dementia Rating scale (CDR) consistent MCI (i.e. CDR $\geq 0.5$ [15];).

\section{Assessments \\ Constitutional and genetic risk factors}

Constitutional risk factors included age, female sex, years of education and self-reported dementia diagnosis in a first-degree relative. APOE4 genotype was determined from Taqman Genotyping of blood, analysed in a single laboratory using QuantStudio12K Flex (www.epad.org).

\section{Cognitive risk factors}

Total Mini-Mental State Examination (MMSE) score was used to derive a measure of global cognitive function [11]. Performance scores from Repeatable Battery for the Assessment of Neuropsychological Status (RBANS) tests of episodic verbal memory, executive function and processing speed were also included as predictors. The RBANS word list learning task assesses episodic verbal memory and involves the immediate recall of 10 semantically unrelated words and is thus scored between 0 and 10; the RBANS coding task assesses executive control function, visual attention and processing speed and is scored according to the number of correct digit-coded responses during a 90-s interval.

\section{Vascular risk factors}

We included the continuous variables of body mass index (BMI), systolic BP and binary medical history variables: hypertensive medication use, past or current diabetes, hypercholesterolaemia and cardiovascular disease (CVD; myocardial infarction, angina pectoris, coronary insufficiency, intermittent claudication, congestive heart failure, arrythmia). Self-reported smoking was included as a binary variable ('ever' versus 'never'). Physical inactivity was binary coded according to self-reported frequency of $<2$ weekly sessions of moderate or vigorous physical activity. The proportion of white matter lesion (WML) volume per whole brain volume was derived from volumetric MRI data-the brain imaging protocol is described elsewhere [40]. 


\section{Composite risk scores}

Specific risk factors were used to derive three alternative composite scores:

CAIDE risk score The original scoring system for CAIDE [25] uses information on age, sex, education, high BP, BMI, total cholesterol and physical inactivity. We allocated a score of 2 to participants who selfreported hypercholesterolaemia (instead of CAIDE's criterion of $>6.5 \mathrm{mmol} / \mathrm{L}$ total cholesterol) in the absence of blood biomarker data in EPAD LCS.

Framingham general cardiovascular disease risk score The sex-adjusted scoring system [6] uses information on age, systolic BP, hypertensive medication, diabetes, total and HDL cholesterol and smoking. In the absence of blood biomarker data for scoring total and HDL cholesterol, we applied the scoring system for self-reported diabetes to self-reported hypercholesterolaemia.

Framingham stroke risk score The sex-adjusted scoring system for the Framingham stroke composite score [7] uses information on age, systolic BP, hypertensive medication, diabetes, smoking, prior CVD, atrial fibrillation and ventricular hypertrophy.

\section{CSF biomarkers}

Cerebral spinal fluid (CSF) samples were measured for amyloid-beta 42 (Aß42) and pathologic tau (p-Tau) in a single laboratory using the Roche Elecsys System. The cut-off for definition of normal Aß42 pathology $(\mathrm{A}+)$ was $<1025 \mathrm{pg} / \mathrm{ml}$, derived by the present authors using Gaussian Mixture Modeling. This approach is based upon previous work in which the assay used in EPAD was validated in two independent cohorts [13]. According to this method, cut-offs are defined either by the intersection point of the two components or by the mean \pm standard deviations. A similar method was used to define the cut-off of $>24 \mathrm{pg} / \mathrm{ml}$ for $\mathrm{p}$-Tau pathology $(\mathrm{T}+)$.

\section{Neurodegeneration biomarker}

Scheltens' visual rating scale [44] for medial temporal lobe atrophy based upon structural MRI images was used as the neurodegenerative marker. Neurodegenerative pathology $(\mathrm{N}+)$ was defined using decade-specific cut-off values to optimise sensitivity and specificity [5]: scores $>1 \mathrm{f}$ participants less than 65 years old, $>1.5$ for 65 to 74 -year-olds, and, and $>2$ for participants older than 75 years.

\section{ATN-defined biological categories}

Participants were categorised into five subgroups as characterised in the ATN Framework [17]: (i) Normal AD biomarkers: $\mathrm{A}-\mathrm{T}-(\mathrm{N})-$

(ii) Alzheimer's pathologic change: $\mathrm{A}+\mathrm{T}-(\mathrm{N})-$

(iii) Alzheimer's disease: $\mathrm{A}+\mathrm{T}+(\mathrm{N}) \pm$

(iv) Alzheimer's and concomitant non-Alzheimer's pathologic change: $\mathrm{A}+\mathrm{T}-(\mathrm{N})+$

(v) Non-AD pathologic change: $\mathrm{A}-\mathrm{T} \pm(\mathrm{N})+; \mathrm{A}-\mathrm{T}+(\mathrm{N})-$

\section{Statistical analysis}

Due to multiple testing throughout, we set significance levels using Bonferroni correction.

Odds ratios and $95 \%$ confidence intervals were estimated in age- and sex-adjusted logistic regression models to observe the extent to which individual risk factors related to brain pathology measured according to $\mathrm{A}+, \mathrm{T}+$ and $\mathrm{N}+$, respectively. Following this, comparisons of risk factors among the five ATN-defined biomarker groups were formally tested using one-way ANOVA or chi-squared tests for continuous and categorical binary variables, respectively. When overall group differences were observed, we investigated which specific group comparisons contributed most to these, by estimating chi-square residuals for categorical binary variables, and conducting Bonferroni tests for continuous variables.

To adjust for the potential confounding effects of age and sex on observed group differences, we conducted multinomial logistic regression models, including age, sex and study site each time, to predict ATN biomarker group membership according to each risk factor. The normal AD biomarker group was the reference category. To understand whether associations had sex or geneticrisk specific effects, we reran the models to include interaction terms between each risk factor with age and APOE4 genotype, respectively.

Finally, we constructed receiver operating characteristic (ROC) curves and estimated areas under the curve (AUC) for models that included the significant risk factors from the previous multinomial logistic regression and each of the composite risk scores, respectively. A basic model (1) included age, sex and APOE4, and subsequent models included:

i) basic model + each significant risk factor in turn;

ii) basic model + all significant risk factors; and

iii) basic model + each of three composite risk scores.

Differences from the basic model were evaluated with the chi-square test.

\section{Results}

Among 1500 participants, 82 individuals had a clinical diagnosis of dementia or MCI. An additional 171 participants were excluded due to CDR score $\geq 0.5$. A further 237 participants had missing data on one or more ATN 
biomarkers, and their exclusion led to an analytic sample of 1010 individuals (mean age $64.6 \pm 6.8$ years; $59 \%$ female). Amyloid-beta pathology $(\mathrm{A}+)$ was observed in 309 (30.6) participants, pathologic tau pathology $(\mathrm{T}+)$ in 158 (15.6\%) and neurodegenerative pathology in 90 (8.9\%) participants. ATN-defined criteria classed 56.1\% $(n=567)$ as 'normal AD biomarkers', $20.9 \%(n=211)$ as 'Alzheimer's pathologic change', 6.6\% $(n=67)$ as 'Alzheimer's disease', $3.1 \%(n=31)$ as 'Alzheimer's and concomitant non-Alzheimer's pathologic change' and 13.3\% $(n=134)$ as 'non-AD pathologic change'.

Risk factors associated with pathology groups $\mathrm{A}+, \mathrm{T}+$ and $\mathrm{N}+$ Individual risk factors were first tested for their respective associations with $\mathrm{A}+, \mathrm{T}+$ and $\mathrm{N}+$, respectively, in logistic regression models that adjusted for age and sex (see Fig. 1 for odds ratios according to constitutional and cognitive risk factors; Fig. 2 for effects according to vascular risk factors.) In terms of constitutional risk factors, we found that age and APOE4 carriership both increased the risk of amyloid $(\mathrm{OR}=1.03,95 \% \mathrm{CI}$ $1.02-1.05, p<0.001$; OR $=2.24,95 \%$ CI $1.68-2.98, p<$ $0.001)$ and tau pathology, respectively $(\mathrm{OR}=1.11$, 95\% CI 1.08-1.14, $p<0.001$; OR $=2.00$, 95\% CI $1.38-$ 2.90, $p<0.001$ ), while the family history of dementia associated with tau positivity only $(\mathrm{OR}=1.55,95 \% \mathrm{CI}$ 1.04-2.32, $p=0.03)$. Lower global cognition scores (MMSE) associated with tau positivity (OR $=0.86,95 \%$ CI $0.76-0.96, p=0.01$ ) while lower executive function scores associated with neurodegeneration $(\mathrm{OR}=0.97$, 95\% CI $0.96-0.99, p=0.01$ ). In terms of cardiovascular risk factors, we found evidence for lower BMI associating with tau pathology $(\mathrm{OR}=0.94,95 \%$ CI $0.90-$
0.98, $p=0.01$ ) whereas amyloid pathology was linked to lower use of hypertensive therapy, lack of diabetes diagnosis and increased WML volumes relative to no pathology $\quad(\mathrm{OR}=0.64, \quad 95 \% \quad \mathrm{CI} \quad 0.43-0.95, \quad p=0.03$; $\mathrm{OR}=0.39, \quad 95 \%$ CI $0.18-0.85, p=0.02 ; \quad \mathrm{OR}=1.010$, 95\% CI 1.005-1.014, $p<0.001)$.

\section{ATN group differences on risk factors}

Table 1 provides a comparison of the ATN pathology groups according to descriptive statistics of each risk factor and CAIDE and Framingham risk scores. The groups differed on mean age, BMI, WML, MMSE and episodic memory and executive function scores, and on the frequency of APOE4 carrier status and family history. Further analyses clarified the specific group comparisons responsible for these differences (Table 2). The main observations were as follows: the group with Alzheimer's disease biomarkers (versus normal AD biomarkers) were on average older, with higher WML volume, lower cognitive scores, higher Framingham stroke scores, and a higher frequency of APOE4 carriers; the Alzheimer's pathologic change group was similar to the normal AD biomarker group in respect to mean age and cognition, and family history frequency, but showed elevated WML volume and a higher frequency of APOE4 carriers that was more consistent with AD pathology. The non-AD pathology group was notable for having the lowest frequency of family history and for a mean WML volume akin to the group with normal AD biomarkers, but with higher mean age and Framingham stroke scores, similar to the Alzheimer's biomarker group.

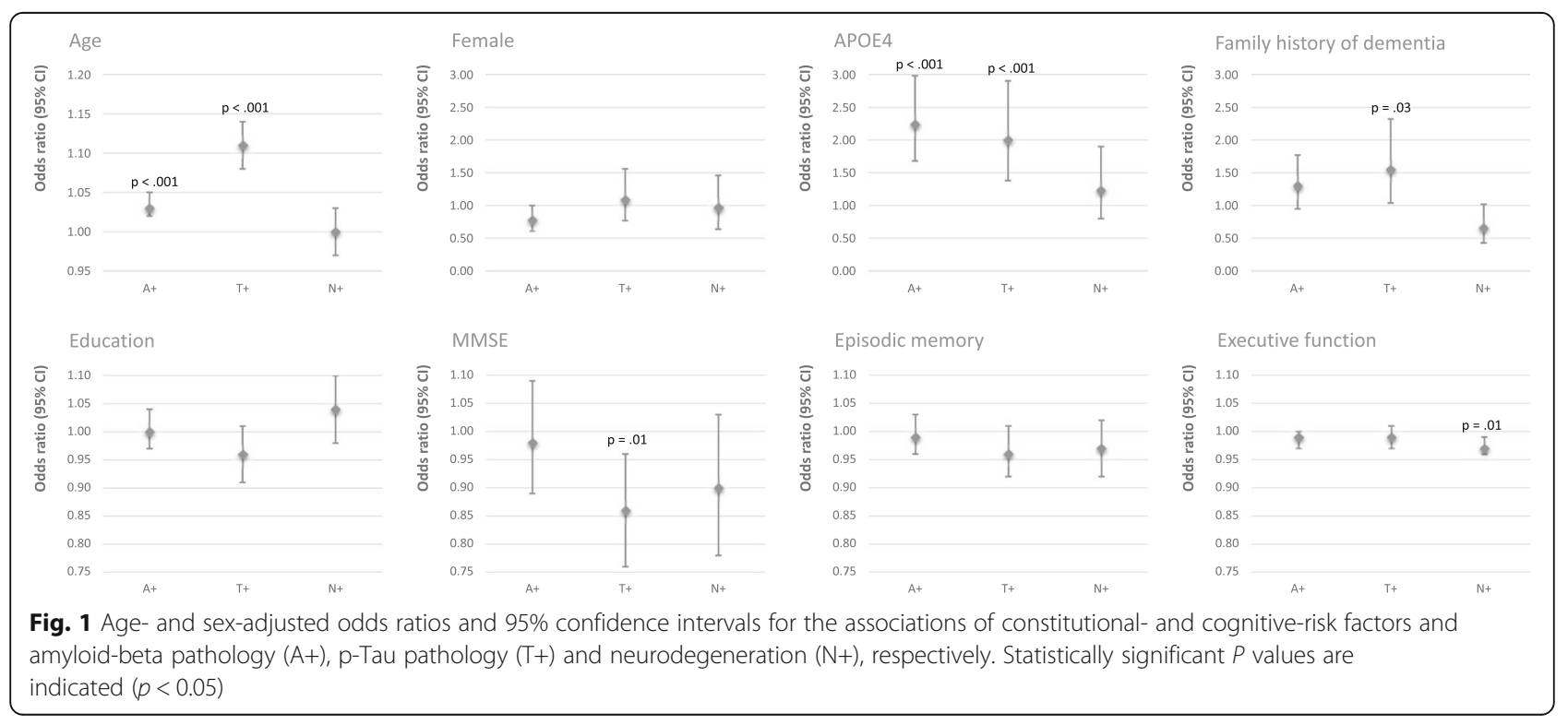




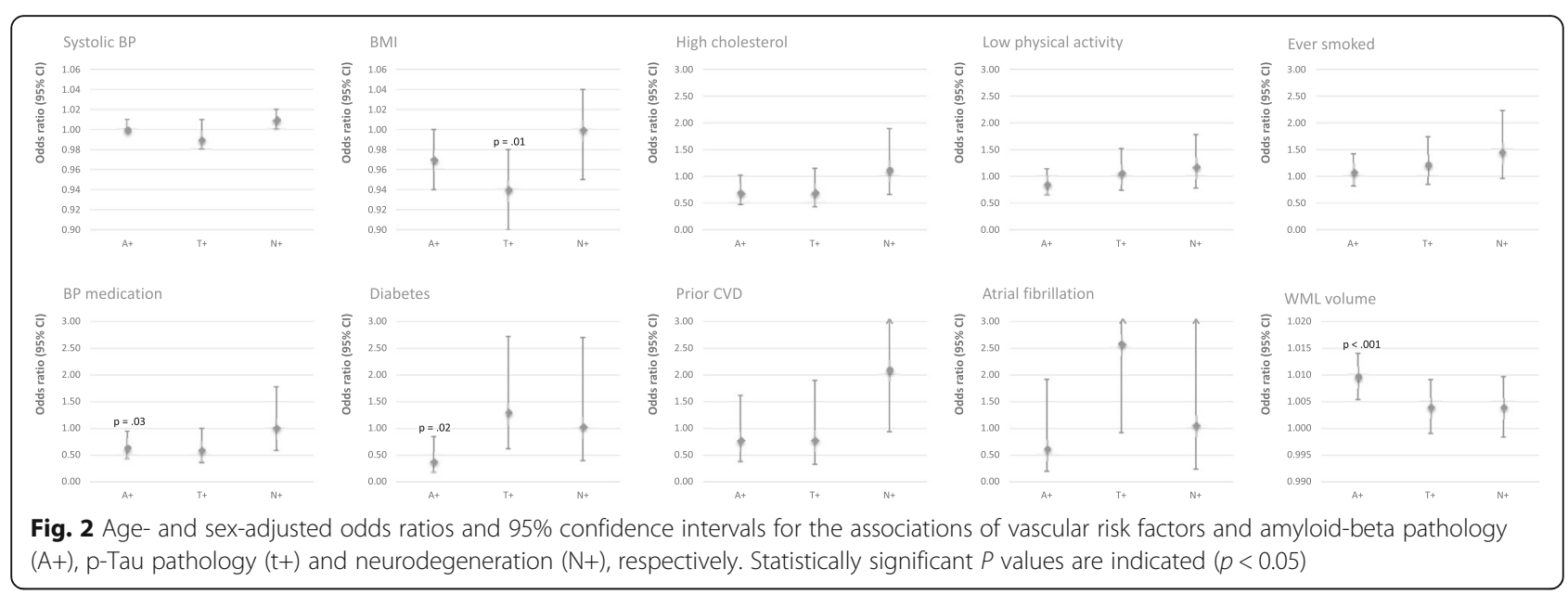

Predicting ATN group membership in age- and sexadjusted models

To adjust for the confounding effects of age and sex prediction of ATN group membership by risk factors were tested in age- and sex-adjusted multinomial logistic regression models using the normal AD biomarker group as the reference (Table 3). Age was significantly greater in the $\mathrm{AD}(\mathrm{RR}=1.14,95 \% \mathrm{CI} 1.09-1.19, p<0.001)$ and non-AD pathology groups $(\mathrm{RR}=1.07,95 \% \mathrm{CI} 1.04-1.10$, $p<0.001)$, but not in Alzheimer's pathologic change $(\mathrm{RR}=1.02$, 95\% CI $1.00-1.05, p=0.08)$ or combined AD and non-AD pathologic change $(\mathrm{RR}=0.97$, 95\%CI $0.92-$ 1.02, $p=0.25)$. APOE4 carriership was predictive of membership to both AD biomarker groups (AD pathologic change: $\mathrm{RR}=1.93,95 \% \mathrm{CI} 1.37-2.72, p<0.001 ; \mathrm{AD}$ pathology: RR 6.48, 95\%CI 3.57-11.8, $p<0.001$ ) but was not significantly different in the non-AD pathology group ( $\mathrm{RR}=1.27$, 95\%CI $0.83-1.93, p=0.27$ ), and $\mathrm{AD} /$ non-AD pathologic change group $(\mathrm{RR}=1.09,95 \% \mathrm{CI}$ $0.50-2.36, p=0.82$ ) relative to the normal AD biomarker group. Family history was predictive of Alzheimer's pathology $(\mathrm{RR}=4.12,95 \% \mathrm{CI} 1.93-8.77, p<0.001)$ but not Alzheimer's pathologic change (RR 1.00, 95\%CI $0.70-1.44, \quad p=0.99), \mathrm{AD} /$ non-AD pathologic change $(\mathrm{RR}=0.63,95 \% \mathrm{CI} 0.29-1.37, p=0.25)$ or non-AD pathology $(\mathrm{RR}=0.75,95 \% \mathrm{CI} 0.50-1.14, p=0.18)$. Among the vascular risk factors, the effect of WML volume survived adjustment for age and sex. WML volume was positively associated with Alzheimer's pathologic change $(\mathrm{RR}=$ 1.008, 95\% CI 1.003-1.014, $p=0.002)$, Alzheimer's pathology $(\mathrm{RR}=1.014,95 \% \mathrm{CI} 1.007-1.020, p<0.001)$ and $\mathrm{AD} /$ non-AD pathologic change $(\mathrm{RR}=1.012 ; 95 \% \mathrm{CI}$ 1.004-1.021, $p=0.005)$. Furthermore, after adjusting for age and sex lower BMI was associated with the Alzheimer's pathology group $(\mathrm{RR}=0.88,95 \% \mathrm{CI} 0.82-0.95, p=$ $0.001)$. There were no vascular risk factors that significantly differentiated non-AD pathology relative to normal AD biomarkers. The group differences in MMSE and RBANS tests were no longer evident after adjustment for age and sex, with the exception that lower MMSE score was associated with $\mathrm{AD}$ pathology $(\mathrm{RR}=$ $0.79,95 \%$ CI $-0.68-0.93, p=0.006$ ).

Multinomial logistic regression models to predict ATN group membership were then tested according to CAIDE and Framingham composite risk scores. On adjustment for age and sex effects, the different composite scores were not predictive of ATN group membership.

\section{Potential interactions between APOE4 and risk factors in predicting ATN}

We repeated the above multinomial logistic regression models with an additional interaction term for each risk factor and APOE4 carriership. The only significant interaction term was between age and APOE4 status, which was significant in predicting Alzheimer's pathologic change versus normal AD biomarkers $(p<0.001)$. A closer examination of this effect showed that APOE4 carriers were younger than non-carriers in participants with normal AD biomarkers $(61.8 \pm 6.1$ vs $65.0 \pm 6.7$ years), while APOE4 carriers were older than noncarriers among those with Alzheimer's pathologic change (65.2 \pm 6.5 vs $64.1 \pm 7.8$ years). We therefore included an interaction term for age and APOE4 in subsequent models of Alzheimer's pathologic change.

\section{ROC models for predicting ATN subgroup pathology versus no pathology}

For the prediction of each ATN pathology group relative to no pathology, the following logistic regression models were run: model 1: age, sex and APOE4 status (including an age X APOE4 interaction term for Alzheimer's pathologic change); model 2: model 1 plus family history; model 3: model 1 plus BMI; model 4: model 1 plus WML volume; model 5: model 1 plus MMSE; model 6: all preceding risk factors; and model $7 \mathrm{a}, \mathrm{b}$ and $\mathrm{c}$ : model 1 plus each composite risk score (Table 4). 
Table 1 Descriptive data on AD risk factors according to ATN subgroups

\begin{tabular}{|c|c|c|c|c|c|c|c|}
\hline & Total & $\begin{array}{l}\text { Normal AD } \\
\text { biomarkers }\end{array}$ & $\begin{array}{l}\text { Alzheimer's } \\
\text { pathologic } \\
\text { change }\end{array}$ & $\begin{array}{l}\text { Alzheimer's } \\
\text { disease }\end{array}$ & $\begin{array}{l}\text { Alzheimer's } \\
\text { and non-AD } \\
\text { pathologic } \\
\text { change }\end{array}$ & $\begin{array}{l}\text { Non-AD pathologic } \\
\text { change }\end{array}$ & $P$ value* \\
\hline$N$ & 1010 & 567 & 211 & 67 & 31 & 134 & \\
\hline \multicolumn{8}{|l|}{ Risk exposures } \\
\hline Age, years & $64.6 \pm 6.8$ & $63.6 \pm 6.6$ & $64.7 \pm 7.1$ & $69.1 \pm 5.9$ & $62.4 \pm 7.1$ & $66.7 \pm 6.2$ & $<0.001$ \\
\hline Sex, female & $58.6 \%$ & $60.1 \%$ & $54.0 \%$ & $56.7 \%$ & $51.6 \%$ & $60.5 \%$ & 0.51 \\
\hline Education, years & $14.7 \pm 3.7$ & $14.8 \pm 3.7$ & $14.9 \pm 3.7$ & $13.9 \pm 3.8$ & $15.8 \pm 3.5$ & $14.5 \pm 3.6$ & 0.14 \\
\hline APOE4 & $37.5 \%$ & $32.2 \%$ & $47.5 \%$ & $69.2 \%$ & $36.7 \%$ & $34.9 \%$ & $<0.001$ \\
\hline Family history & $68.5 \%$ & $72.1 \%$ & $69.2 \%$ & $86.6 \%$ & $61.3 \%$ & $61.2 \%$ & 0.003 \\
\hline Systolic BP & $134.8 \pm 17.8$ & $133.5 \pm 17.6$ & $136.4 \pm 17.9$ & $137.8 \pm 17.0$ & $136.9 \pm 18.1$ & $136.0 \pm 18.8$ & 0.10 \\
\hline BMI & $26.4 \pm 4.3$ & $26.4 \pm 4.3$ & $26.5 \pm 4.3$ & $24.8 \pm 3.7$ & $27.2 \pm 4.5$ & $26.2 \pm 4.6$ & 0.03 \\
\hline High cholesterol & $16.3 \%$ & $17.3 \%$ & $14.7 \%$ & $11.9 \%$ & $9.7 \%$ & $17.2 \%$ & 0.59 \\
\hline Physical inactivity & $43.0 \%$ & $43.3 \%$ & $38.3 \%$ & $43.3 \%$ & $36.7 \%$ & $45.9 \%$ & 0.61 \\
\hline Ever smoked & $54.2 \%$ & $52.1 \%$ & $53.1 \%$ & $58.2 \%$ & $60.0 \%$ & $59.4 \%$ & 0.50 \\
\hline BP medication & $15.5 \%$ & $17.6 \%$ & $13.3 \%$ & $13.4 \%$ & $16.1 \%$ & $15.7 \%$ & 0.63 \\
\hline Diabetes & $4.5 \%$ & $4.9 \%$ & $1.9 \%$ & $6.0 \%$ & $0.0 \%$ & $8.2 \%$ & 0.05 \\
\hline Prior CVD & $4.1 \%$ & $3.7 \%$ & $2.8 \%$ & $4.5 \%$ & $6.5 \%$ & $5.2 \%$ & 0.75 \\
\hline Atrial fibrillation & $1.9 \%$ & $1.6 \%$ & $1.4 \%$ & $1.5 \%$ & $0.0 \%$ & $3.7 \%$ & 0.44 \\
\hline WML volume* & $12.9 \pm$ & $9.3 \pm 26.2$ & $17.3 \pm 35.2$ & $27.8 \pm 48.5$ & $24.1 \pm 42.8$ & $11.2 \pm 27.8$ & $<0.001$ \\
\hline MMSE & $28.8 \pm 1.3$ & $28.9 \pm 1.3$ & $28.9 \pm 1.2$ & $28.2 \pm 1.9$ & $29.0 \pm 1.3$ & $28.6 \pm 1.2$ & $<0.001$ \\
\hline $\begin{array}{l}\text { Episodic verbal } \\
\text { memory }\end{array}$ & $29.1 \pm 4.2$ & $29.4 \pm 4.2$ & $29.0 \pm 4.2$ & $27.4 \pm 4.5$ & $29.7 \pm 3.6$ & $28.5 \pm 4.3$ & 0.002 \\
\hline Executive function & $46.3 \pm 10.3$ & $47.5 \pm 9.9$ & $45.5 \pm 10.4$ & $41.6 \pm 9.5$ & $47.5 \pm 11.8$ & $44.3 \pm 11.2$ & $<0.001$ \\
\hline \multicolumn{8}{|l|}{ Composite scores } \\
\hline CAIDE & $6.22 \pm 1.83$ & $6.16 \pm 1.80$ & $6.19 \pm 1.87$ & $6.48 \pm 2.00$ & $6.00 \pm 1.60$ & $6.42 \pm 1.87$ & 0.43 \\
\hline Framingham CVD & $14.0 \pm 3.6$ & $13.7 \pm 3.6$ & $13.8 \pm 3.7$ & $15.3 \pm 3.3$ & $13.2 \pm 3.3$ & $14.7 \pm 3.3$ & $<0.001$ \\
\hline Framingham stroke & $9.32 \pm 4.04$ & $8.82 \pm 3.98$ & $9.33 \pm 3.97$ & $11.13 \pm 3.66$ & $8.97 \pm 3.35$ & $10.55 \pm 4.25$ & $<0.001$ \\
\hline
\end{tabular}

Data points represent means \pm SDs for continuous variables and percentages for categorical binary variables

*P values are significance levels for one-way ANOVA or chi-squared tests assessing group differences on continuous and categorical binary variables respectively; those in bold survive Bonferroni correction $(0.5 / 21=0.024)$

Abbreviations: A $ß$-amyloid pathology, $T$ P-Tau pathology, $N$ neurodegenerative pathology

In the basic model, AUC was greatest for predicting $\mathrm{AD}$ pathology $(\mathrm{AUC}=0.82,95 \% \mathrm{CI} 0.77-0.88)$, followed by Alzheimer's pathologic change (AUC $=0.63,95 \% \mathrm{CI}$ $0.58-0.68$ ) and non-AD pathology (AUC $=0.63,95 \% \mathrm{CI}$ $0.58-0.68)$ and then $\mathrm{AD}$ and non- $\mathrm{AD}$ pathologic change (AUC $=0.56,95 \%$ CI $0.44-0.68)$. The significant effect of family history in model 2 for predicting Alzheimer's pathology did not lead to a more predictive model than model 1 (AUC $=0.84,95 \% \mathrm{CI} 0.79$ to 0.89 ), as it may have displaced some of the APOE4 effects. Further inclusion of individual risk factors to model 1 did not improve its prediction of Alzheimer's pathology. However, in model 6, combining family history, BMI, MMSE and WML volume with basic model risk factors significantly improved the AD pathology AUC (AUC $=0.89,95 \% \mathrm{CI}$ $0.85-0.93, p<0.001$; Fig. 3). Only the addition of WML to the basic model seemed to improve the prediction of Alzheimer's pathologic change (AUC $=0.66,95 \% \mathrm{CI} 0.61$ to $0.71, p=0.02$ ), although this did not survive Bonferroni correction. There were no significant improvements observed from the basic model in predicting $A D$ and non-AD pathologic change and non-AD pathology, respectively, versus no pathology. Addition of the three composite risk scores made no improvement over the basic models for any pathology group.

\section{Discussion}

In this analysis, we found that among older cognitively healthy adults, Alzheimer's disease pathology and Alzheimer's pathologic change defined by the ATN Framework are predicted by genetic factors (i.e. APOE4) and greater WML volume. Alzheimer's disease pathology is 
Table 2 ATN group differences by risk factor

\begin{tabular}{|c|c|c|c|c|c|c|}
\hline & & $\begin{array}{l}\text { Normal AD } \\
\text { biomarkers }\end{array}$ & $\begin{array}{l}\text { Alzheimer's } \\
\text { pathologic } \\
\text { change }\end{array}$ & $\begin{array}{l}\text { Alzheimer's } \\
\text { disease }\end{array}$ & $\begin{array}{l}\text { Alzheimer's } \\
\text { and non-AD } \\
\text { pathologic change }\end{array}$ & Non-AD pathology \\
\hline \multicolumn{7}{|c|}{ Bonferroni test for subgroup comparisons } \\
\hline \multicolumn{2}{|l|}{ Risk factors (continuous) } & $P$ value & $P$ value & $P$ value & $P$ value & \\
\hline \multirow[t]{4}{*}{ Age } & Alzheimer's pathologic change & 1.0 & & & & \\
\hline & Alzheimer's disease & $<0.001$ & $<0.001$ & & & \\
\hline & AD/non-AD pathologic change & 1.0 & 0.82 & $<0.001$ & & \\
\hline & Non-AD pathology & $<0.001$ & 0.07 & 0.15 & 0.02 & - \\
\hline \multirow[t]{4}{*}{ WML volume* } & Alzheimer's pathologic change & 0.02 & & & & \\
\hline & Alzheimer's disease & $<0.001$ & 0.14 & & & \\
\hline & AD/non-AD pathologic change & 0.10 & 1.0 & 1.0 & & \\
\hline & Non-AD pathology & 1.0 & 0.72 & 0.003 & 0.33 & - \\
\hline \multirow[t]{4}{*}{ Framingham CVD } & Alzheimer's pathologic change & 1.0 & & & & \\
\hline & Alzheimer's disease & 0.02 & 0.03 & & & \\
\hline & AD /non-AD pathologic change & 1.0 & 1.0 & 0.07 & & \\
\hline & Non-AD pathology & 0.08 & 0.18 & 1.0 & 0.30 & - \\
\hline \multirow[t]{4}{*}{ Framingham stroke } & Alzheimer's pathologic change & 1.0 & & & & \\
\hline & Alzheimer's disease & $<0.001$ & 0.01 & & & \\
\hline & AD/non-AD pathologic change & 1.0 & 1.0 & 0.13 & & \\
\hline & Non-AD pathology & $<0.001$ & 0.06 & 1.0 & 0.49 & - \\
\hline \multirow[t]{4}{*}{ MMSE } & Alzheimer's pathologic change & 1.0 & & & & \\
\hline & Alzheimer's disease & 0.005 & 0.003 & & & \\
\hline & AD/non-AD pathologic change & 1.0 & 1.0 & 0.08 & & \\
\hline & Non-AD pathology & 1.0 & 0.73 & 0.35 & 1.0 & - \\
\hline \multirow[t]{4}{*}{ Verbal learning } & Alzheimer's pathologic change & 1.0 & & & & \\
\hline & Alzheimer's disease & 0.02 & 0.08 & & & \\
\hline & AD/non-AD pathologic change & 1.0 & 1.0 & 0.13 & & \\
\hline & Non-AD pathology & 1.0 & 1.0 & 1.0 & 1.0 & - \\
\hline \multirow[t]{4}{*}{ Coding } & Alzheimer's pathologic change & 1.0 & & & & \\
\hline & Alzheimer's disease & $<0.001$ & 0.09 & & & \\
\hline & AD/non-AD pathologic change & 1.0 & 1.0 & 0.09 & & \\
\hline & Non-AD pathology & 0.12 & 1.0 & 0.84 & 1.0 & - \\
\hline \multicolumn{7}{|c|}{ Chi-square residuals test for evaluating subgroup contribution to group differences } \\
\hline \multicolumn{2}{|l|}{ Risk factors (binary) } & Adjusted $R$ & Adjusted $R$ & Adjusted $R$ & Adjusted $R$ & Adjusted $R$ \\
\hline \multicolumn{2}{|l|}{ APOE4 } & -4.74 & 3.18 & 5.45 & -0.10 & -0.65 \\
\hline \multicolumn{2}{|l|}{ Family history } & -0.22 & 0.25 & 3.28 & -0.87 & -1.92 \\
\hline
\end{tabular}

$P$ values in bold survive Bonferroni correction $(0.5 / 56=0.009)$. Adjusted standardised residuals $(R)$ in bold represent significant subgroup effects, i.e. $R>2$ indicates that the number of cases with a risk factor within the ATN subgroup is significantly larger than expected if the null hypothesis is true ( $p<0.05$ ); $R<-2$ indicates that the numbers of cases with a risk factor within the ATN subgroup is significantly smaller than expected if the null hypothesis is true

also predicted by positive family history of dementia, lower BMI and lower MMSE score, and combined with WML volume, these improved the discriminative accuracy of a ROC model predicting Alzheimer's disease versus normal AD biomarkers by $7 \%$, compared to a model including age, sex and APOE e4. Models that included previously validated composite risk scores for dementia, rather than cumulative risk factors, showed no improvement. Greater age was the only predictor of non-AD pathology among cognitively healthy adults, and higher WML volume was the only significant predictor of combined $\mathrm{AD} /$ non-AD pathologic change.

The ATN framework was proposed as an unbiased descriptive approach for defining distinct multidomain 


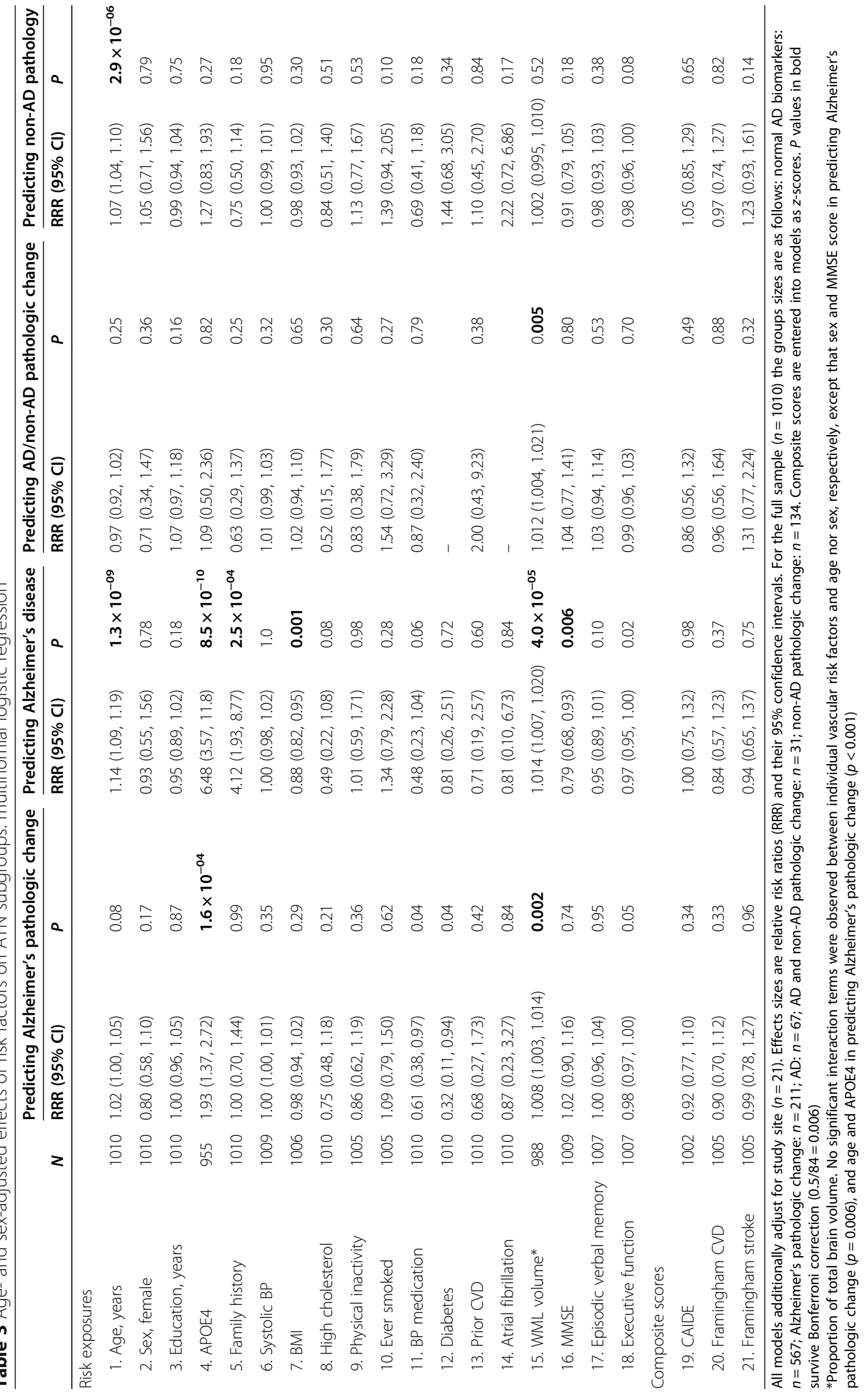




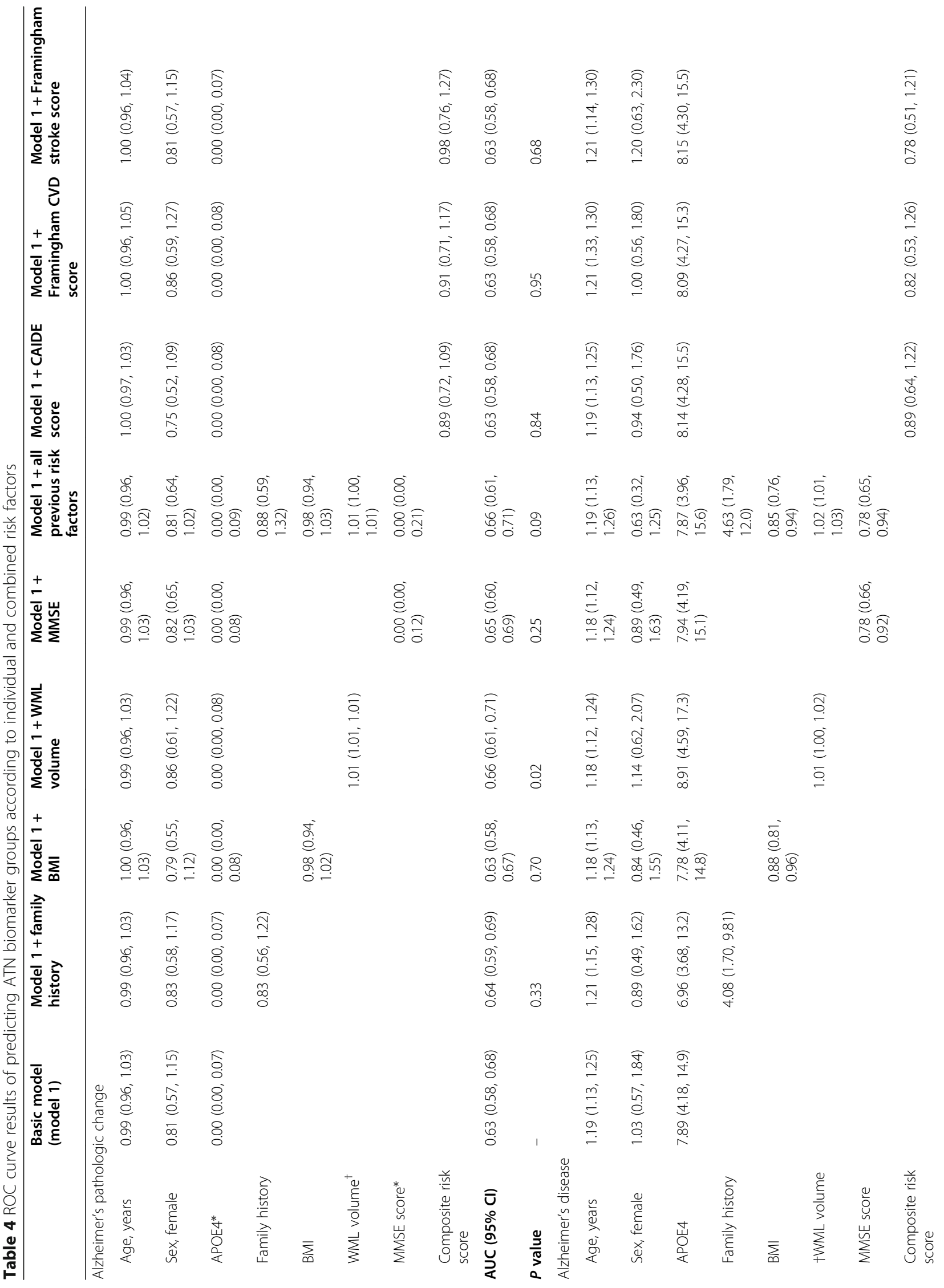




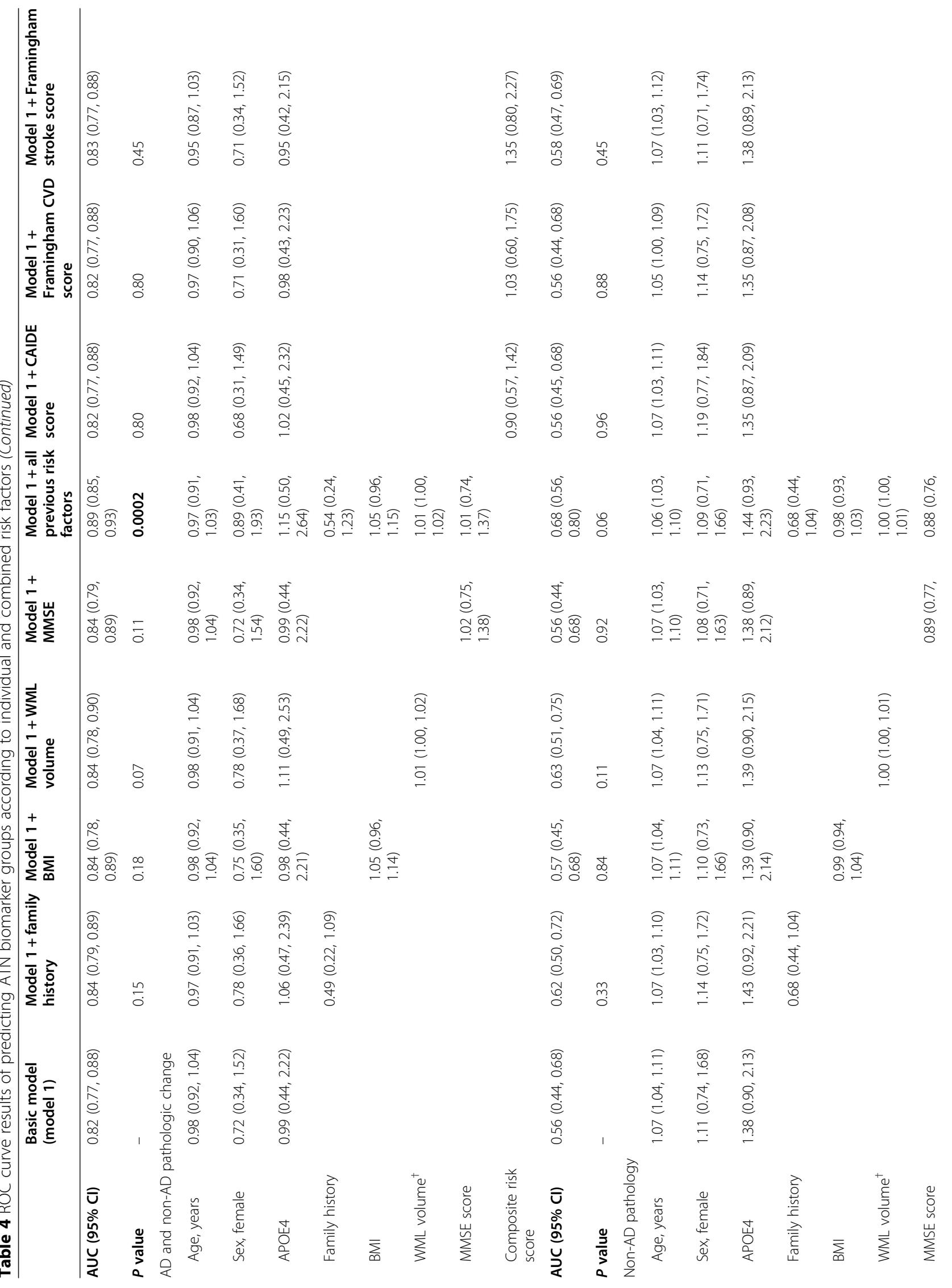




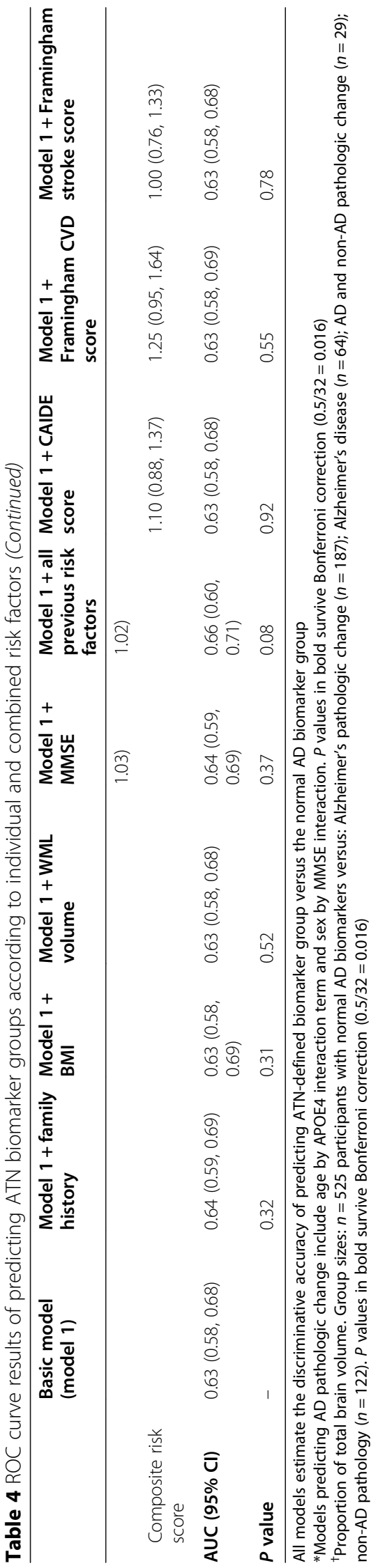



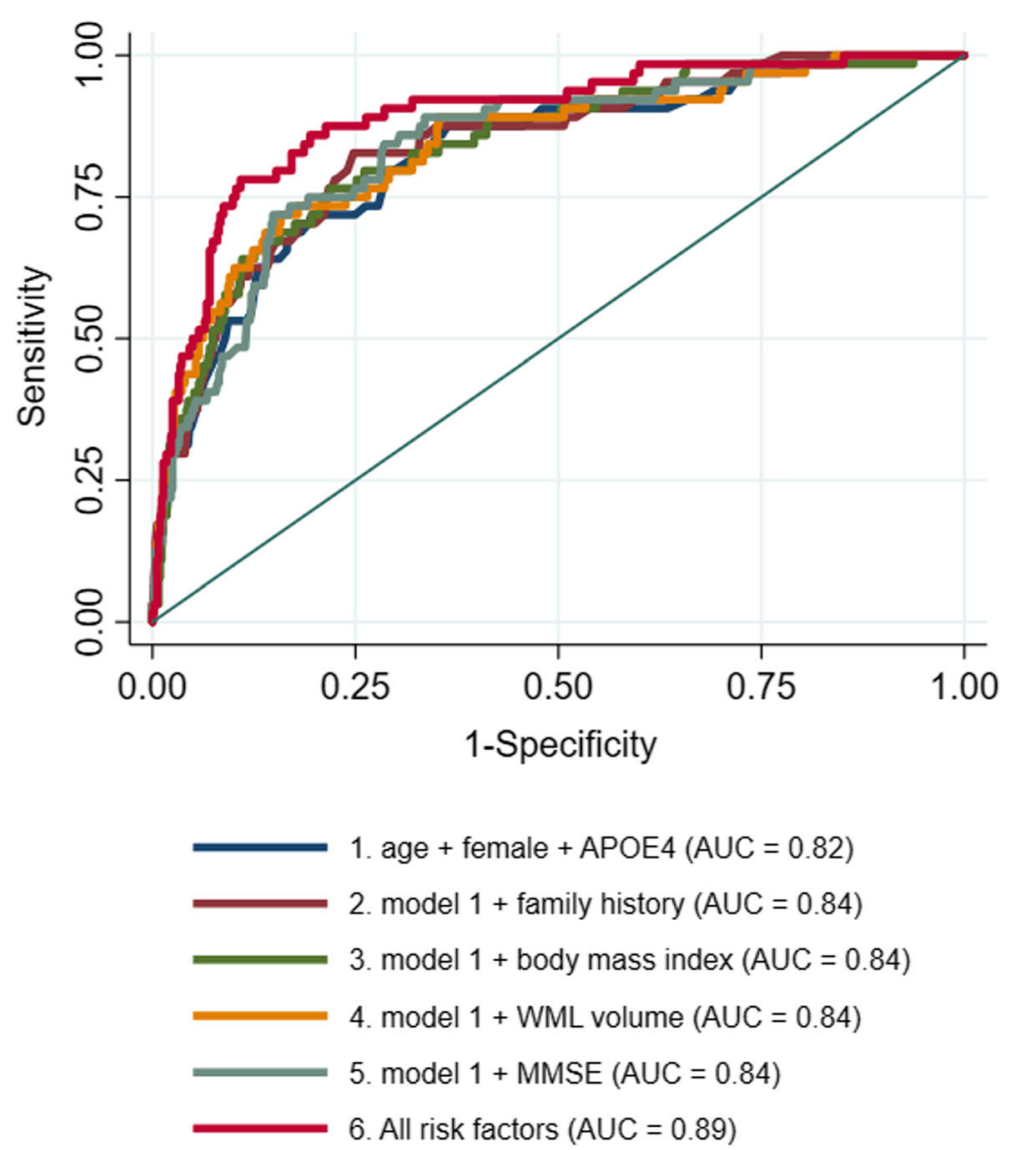

Fig. 3 ROC curve showing improvement to the discriminative accuracy of predicting Alzheimer's disease vs normal AD biomarkers by cumulative risk factors

biomarker profiles at the individual person level [16]. The ATN framework departed from previous criteria by segregating pathologic tau measures from other markers of neuronal injury, as means of improving the ability to differentiate $\mathrm{AD}$ from non-AD pathology. The relevance of the ATN system to preclinical disease was demonstrated by data showing that among cognitively healthy individuals, ATN AD pathology status associates with worse cognition [3]. Our analysis extends these results by demonstrating in the largest reported cognitively healthy ageing group to-date that close to half of all participants can be classified as abnormal through ATN criteria $(20.9 \%$ Alzheimer's pathologic change, 6.6\% Alzheimer's disease pathology, 3.1\% combined AD and non-AD pathologic change and $13.3 \%$ non-AD pathology).

The clear utility of ATN is counterweighed by its reliance on sampling AD biomarkers which is invasive and costly. Therefore, accurate prediction of ATN status through more accessible means is a priority. Our analysis demonstrated that a base model encompassing the best validated constitutional risk factors for $\mathrm{AD}$ in a preclinical group (age, sex and APOE4 carriership) performed well (AUC 0.82) in predicting AD pathology, with the model being considerably less accurate for $A D$ pathologic change and non-AD pathology (AUCs 0.63 and 0.63 , respectively), and particularly combined $\mathrm{AD}$ and non-AD pathologic change (AUC 0.56). A recent study showed similar AUCs (0.83 in Pathfinder and 0.82 in Alzheimer's Disease Neuroimaging Initiative cohorts, respectively) for predicting amyloid positivity using a model combining age, APOE4 and episodic memory [35]. While this analysis was not able to differentiate between $\mathrm{AD}$ pathology (i.e. $\mathrm{A}+\mathrm{T}+\mathrm{N}+/-$ ) and $\mathrm{AD}$ pathologic change $(\mathrm{A}+\mathrm{T}-\mathrm{N}-)$, the two cohorts had a substantial proportion of $\mathrm{MCI}$ and subjective memory impairment participants, which makes it likely that they had significant tau pathology. The predictive power of APOE4 for both amyloid and tau positivity in preclinical disease is underlined by another analysis from our group demonstrating that APOE4 carriership is by far the best factor interacting with age on the timing of rapid accumulation of amyloid among cognitively healthy individuals [28].

Our Alzheimer's disease pathology base model (age, sex and APOE4) were improved by the addition of BMI 
and WML volume combined with family history and MMSE. We found that it was low BMI that drove the improvement, which replicates established data on a bidirectional relationship between $\mathrm{BMI}$ and dementia risk: higher BMI in mid-age and lower BMI in the period immediately before diagnosis $[23,36]$. A recent report among initially cognitively healthy women confirmed that low BMI predicts dementia conversion within 5 years but not for longer periods [10]. The lowering of BMI in the years proximal to dementia onset has been attributed to disease prodrome associated changes in eating behaviours, activity and metabolism. There was a small degree of improvement to the $\mathrm{AD}$ pathology models by WML volume which is in line with evidence that cerebrovascular pathology co-exists with AD pathology [45]. White matter changes have a close relationship with cardiovascular risk factors such as hypertension [51] and diabetes [48] and are predictive of dementia [2]. Deficits in the cerebral microcirculation are thought to play a role in the propagation of $\mathrm{AD}$ pathology through restriction of blood flow, neuroinflammation and amyloid clearance mechanisms $[8,22]$. The ATN position paper thus highlighted the potential inclusion of a vascular (V) factor in future revisions of the framework [17]. The currently reported marginal association of WML to AD pathology but not other ATN groups in pre-syndromal individuals warrants further investigation of WML volume as a potential vascular biomarker in future revisions of the ATN framework.

In contrast to BMI and WML volume, we did not observe any improvement to the base model by the addition of the best validated composite risk scores for dementia (CAIDE, Framingham cardiovascular and stroke score). The reason for this may lie in the fact that they were either developed (CAIDE) or repurposed (Framingham scores) to estimate the risk for imminent dementia conversion rather than for use in the potentially more heterogeneous and less well-defined preclinical dementia phenotype. Also, the data reduction inherent in risk scores likely reduces their power to discriminate between pathological and non-pathological preclinical states. Our data suggest that continuous cardiovascular risk factors, as well as proxies of subclinical cerebrovascular disease such as WML volume, may be more relevant in this disease stage.

The analysis was also notable for the relatively poor performance of the prediction models for non-AD pathology. This result is unsurprising given the known low prevalence of APOE4 genotype among individuals with suspected non-Alzheimer disease pathology (SNAP) [26, 32]. SNAP is a biomarker-defined condition (amyloid negative, but evidence for neurodegeneration and/or increased tau protein) affecting approximately $23 \%$ of cognitively normal adults aged 65 or above [18]. SNAP is heterogenous in terms of progression as well as clinical phenotype (e.g. cognitive profile) that make its distinction challenging and our current analysis reinforces this by showing the low predictive value of risk factors typically associated with $\mathrm{AD}$ risk.

In future, ATN prediction is likely to be improved by biomarkers that are more phase-specific to the preclinical disease stage. Specifically, recent improvement to plasma assay sensitivity has allowed the detection of amyloid: amyloid (Abeta 42/40), tau (ptau-181) and neurodegeneration (neurofilament light). Abeta $42 / 40$ has been shown to correlate with amyloid positivity [33] while increases levels of NfL are evident 10 years prior to estimated disease onset in carriers of autosomally dominant mutations for early-onset AD [50]. Most recently, p-tau181 was shown to correlate strongly with both amyloid and tau PET positivity, tau Braak staging [19] as well as to discriminate AD from other causes of dementia, e.g. fronto-temporal dementia [49]. Others have already demonstrated improved amyloid positivity prediction through the addition of Abeta 42/40 but not NfL to age, APOE4 and cognition models [35]. Further gains may be possible through the rapidly developing digital technologies which offer previously unattainable data granularity in terms of cognitive and functional trajectory, via passive (e.g. interaction with digital technology, navigational skills through GPS) and active (e.g. smartphone cognitive testing) data collection $[4,27,29]$.

\section{Limitations}

Previous validation of the CAIDE score was based upon a sample with vascular measures at midlife and 20-year follow-up of AD pathological risk, and such distal relationships offer some evidence for the direction of association. Apart from testing for confounders with the inclusion of select covariates, we therefore cannot comment on the direction of association in the current study. A further limitation is that whereas the CAIDE score was validated according to vascular risk scores at on average 50 years of age (and Framingham scores at age 55 years), our sample was 65 years on average. We know that certain CVD risk factors, i.e. BMI and blood pressure, change in their association with dementia risk and/or cognitive impairment with age. Therefore, we may not have expected to see the same set of vascular risk factors predicting AD pathology than were observed in the somewhat younger Finnish and British Whitehall II samples.

We were limited to looking at the contemporaneous associations between vascular risk factors and ATN biomarkers, and a longitudinal analysis of change in these biomarkers would help to illuminate the present study's findings. 
Finally, healthy volunteer cohort studies are limited through a self-selection bias which may lead to individuals unrepresentative of the general population being more likely to volunteer. While this is an important limitation, this initial analysis allows future work to validate the ATN prediction models in larger cohorts, e.g. Dementias Platform UK Clinical Studies Register (www. greatmindsfordementia.org), Brain Health Registry which may be less prone to this bias due to the virtue of their larger size (over 50k participants) and lower bar for participation (online-only data collection) relative to an observational study such as EPAD.

\section{Conclusions}

Despite their ease of use, brain health composite risk scores did not offer an advantage in the detection of either $\mathrm{AD}$ or non-AD preclinical pathology relative to a prediction model consisting of age, sex and APOE4 genotype in our sample of older, healthy adults. Further advances to disease and phase-specific ATN prediction may be possible through novel plasma biomarkers and digital technologies.

\section{Acknowledgements}

We thank the EPAD LCS research participants and the study partners.

\section{Authors' contributions}

$\mathrm{IK}$ and $\mathrm{CdB}$ formulated the research question and plan. CC led on the data analysis. IK and CC prepared the first manuscript draft. VR, JR and CdB reviewed and contributed to the final manuscript. The authors read and approved the final manuscript.

\section{Funding}

This work has received funding from the EU/EFPIA Innovative Medicines Initiative Joint Undertaking EPAD grant agreement number 115736, and the Medical Research Council (MRC)-funded Dementias Platform UK (MR/ L023784/2). IK has received support for this work from the Oxford Health Biomedical Research Centre.

\section{Availability of data and materials}

The dataset analysed (EPAD LCS V1500; doi:https://doi.org/10.34688/epadlcs_ v500.1_20.04.29) during the current study is freely available through the EPAD LCS repository (http://ep-ad.org/erap/).

\section{Ethics approval and consent to participate}

Data for this study were approved by EPAD LCS (191024_UOX_CAC_001). The EPAD LCS protocol and materials were approved by the Independent Ethics Committees local to each site. The study was designed and conducted in accordance with Good Clinical Practice principles and with the ethical principles of the Declaration of Helsinki.

\section{Consent for publication}

Not applicable.

\section{Competing interests}

$J G$ was the recipient of an MRC grant for staff, which included a salary for CMC and IK. The authors declare no other conflicts of interest.

\section{Author details}

'Department of Psychiatry, University of Oxford, Warneford Hospital, Oxford OX3 7JX, UK. ${ }^{2}$ Alzheimer Center Amsterdam, Amsterdam UMC, Amsterdam, Netherlands.
Received: 11 August 2020 Accepted: 20 October 2020

Published online: 09 November 2020

\section{References}

1. Alonso A, Mosley TH, Gottesman RF, Catellier D, Sharrett R, Coresh J. Risk of dementia hospitalization associated with cardiovascular risk factors in midlife and older age: the Atherosclerosis Risk in the Communities (ARIC) study. J Neurol Neurosurg Psychiatry. 2009;80:1194-201 https://doi.org/10. 1136/jnnp.2009.176818.

2. Brickman AM, Provenzano FA, Muraskin J, Manly JJ, Blum S, Apa Z, Stern Y, Brown TR, Luchsinger JA, Mayeux R. Regional white matter hyperintensity volume, not hippocampal atrophy, predicts incident Alzheimer disease in the community. Arch Neurol. 2012;69:1621-7 https://doi.org/10.1001/ archneurol.2012.1527.

3. Burnham SC, Coloma PM, Li Q-X, Collins S, Savage G, Laws S, Doecke J, Maruff P, Martins RN, Ames D, Rowe CC, Masters CL, Villemagne VL. Application of the NIA-AA research framework: towards a biological definition of Alzheimer's disease using cerebrospinal fluid biomarkers in the AIBL study. J Prev Alzheimer's Dis. 2019;6:248-55 https://doi.org/10.14283/ jpad.2019.25.

4. Chinner A, Blane J, Lancaster C, Hinds C, Koychev I. Digital technologies for the assessment of cognition: a clinical review. Evid Based Ment Health. 2018;21:67-71 https://doi.org/10.1136/eb-2018-102890.

5. Claus JJ, Staekenborg SS, Holl DC, Roorda JJ, Schuur J, Koster P, Tielkes CEM, Scheltens P. Practical use of visual medial temporal lobe atrophy cut-off scores in Alzheimer's disease: validation in a large memory clinic population. Eur Radiol. 2017;27:3147-55 https://doi.org/10.1007/s00330-0164726-3.

6. D'Agostino RB, Vasan RS, Pencina MJ, Wolf PA, Cobain M, Massaro JM, Kannel WB. General cardiovascular risk profile for use in primary care: the Framingham heart study. Circulation. 2008;117:743-53 https://doi.org/10. 1161/CIRCULATIONAHA.107.699579.

7. D'Agostino RB, Wolf PA, Belanger AJ, Kannel WB. Stroke risk profile: adjustment for antihypertensive medication the Framingham study. Stroke. 1994:25:40-3 https://doi.org/10.1161/01.STR.25.1.40.

8. de la Torre J. Cerebral hemodynamics and vascular risk factors: setting the stage for Alzheimer's disease. J Alzheimers Dis. 2012;32:553-67 https://doi. org/10.3233/JAD-2012-120793.

9. Elias MF, Sullivan LM, D'Agostino RB, Elias PK, Beiser A, Au R, Seshadri S, DeCarli C, Wolf PA. Framingham stroke risk profile and lowered cognitive performance. Stroke. 2004;35:404-9 https://doi.org/10.1161/01.STR. 0000103141.82869 .77$.

10. Floud S, Simpson RF, Balkwill A, Brown A, Goodill A, Gallacher J, Sudlow C, Harris P, Hofman A, Parish S, Reeves GK, Green J, Peto R, Beral V. Body mass index, diet, physical inactivity, and the incidence of dementia in 1 million UK women. Neurology. 2020;94:e123-32 https://doi.org/10.1212/WNL. 0000000000008779 .

11. Folstein MF, Folstein SE, McHugh PR. "A Mini-Mental State": a practical method for grading the cognitive state of patients for the clinician. J Psychiatr Res. 1975;12:189-98.

12. Freitag MH, Peila R, Masaki K, Petrovitch H, Ross GW, White LR, Launer $L$. Midlife pulse pressure and incidence of dementia: the Honolulu-Asia Aging Study. Stroke. 2006;37:33-7 https://doi.org/10.1161/01.STR.0000196941. 58869.2d.

13. Hansson O, Seibyl J, Stomrud E, Zetterberg H, Trojanowski JQ, Bittner T, Lifke V, Corradini V, Eichenlaub U, Batrla R, Buck K, Zink K, Rabe C, Blennow K, Shaw LM. CSF biomarkers of Alzheimer's disease concord with amyloid- $\beta$ PET and predict clinical progression: a study of fully automated immunoassays in BioFINDER and ADNI cohorts. Alzheimers Dement. 2018; 14:1470-81 https://doi.org/10.1016/j.jalz.2018.01.010.

14. Hernán MA, Alonso A, Logroscino G. Cigarette smoking and dementia: potential selection bias in the elderly. Epidemiology. 2008;19:448-50 https:/ doi.org/10.1097/EDE.0b013e31816bbe14.

15. Hughes C, Berg L, Danziger W, Coben L, Martin R. A new clinical scale for the staging of dementia. Br J Psychiatry. 1982;140:566-72.

16. Jack CR, Bennet DA, Blennow K, Carrillo MC, Feldman HH, Frisoni GB, Hampel HJ, Jagust WJ, Johnson KA, Knopman DS, Petersen RC, Scheltens P, Sperling RA, Dubois B. A/T/N: An unbiased descriptive classification scheme for Alzheimer disease biomarkers. Neurology. 2016a;87:539-47.

17. Jack CR, Bennett DA, Blennow K, Carrillo MC, Dunn B, Haeberlein SB, Holtzman DM, Jagust W, Jessen F, Karlawish J, Liu E, Molinuevo JL, Montine 
T, Phelps C, Rankin KP, Rowe CC, Scheltens P, Siemers E, Snyder HM, Sperling R, Elliott C, Masliah E, Ryan L, Silverberg N. NIA-AA Research Framework: toward a biological definition of Alzheimer's disease. Alzheimers Dement. 2018;14:535-62 https://doi.org/10.1016/j.jalz.2018.02.018.

18. Jack CR, Knopman DS, Chételat G, Dickson D, Fagan AM. Suspected nonAlzheimer disease pathophysiology — concept and controversy. Nat Rev Neurol. 2016b;12:117-24 https://doi.org/10.1038/nrneurol.2015.251. Suspected.

19. Janelidze $S$, Mattsson N, Palmqvist S, Smith R, Beach T, Serrano G, Chai X, Proctor N, Eichenlaub U, Zetterberg H, Blennow K, Reiman E, Stomrud E, Dage J, Hansson O. Plasma P-tau181 in Alzheimer's disease: relationship to other biomarkers, differential diagnosis, neuropathology and longitudinal progression to Alzheimer's dementia. Nat Med. 2020;26:379-86 https://doi. org/10.1038/s41591-020-0755-1.

20. Kaffashian S, Dugravot A, Elbaz A, Shipley MJ, Sabia S, Kivimäki M, SinghManoux A. Predicting cognitive decline: a dementia risk score vs the Framingham vascular risk scores. Neurology. 2013;80:1300-6 https://doi.org/ 10.1212/WNL.0b013e31828ab370.

21. Kaffashian S, Dugravot A, Nabi H, Batty GD, Brunner E, Kivimki M, SinghManoux A. Predictive utility of the Framingham general cardiovascular disease risk profile for cognitive function: evidence from the Whitehall II study. Eur Heart J. 2011;32:2326-32 https://doi.org/10.1093/eurhearti/ehr133.

22. Kalaria RN. Linking cerebrovascular defense mechanisms in brain ageing and Alzheimer's disease. Neurobiol. Aging. 2009;30:1512-4.

23. Kivimäki M, Luukkonen R, Batty GD, Ferrie JE, Pentti J, Nyberg ST, Shipley MJ, Alfredsson L, Fransson El, Goldberg M, Knutsson A, Koskenvuo M, Kuosma E, Nordin M, Suominen SB, Theorell T, Vuoksimaa E, Westerholm P, Westerlund H, Zins M, Kivipelto M, Vahtera J, Kaprio J, Singh-Manoux A, Jokela M. Body mass index and risk of dementia: analysis of individual-level data from 1.3 million individuals. Alzheimer's Dement. 2018;14:601-9 https://doi.org/10. 1016/j.jalz.2017.09.016.

24. Kivipelto M, Helkala EL, Laakso MP, Hänninen T, Hallikainen M, Alhainen $K$, Soininen $\mathrm{H}$, Tuomilehto J, Nissien A. Midlife vascular risk factors and Alzheimer's disease in later life: longitudinal, population based study. $\mathrm{Br}$ Med J. 2001;322:1447-51 https://doi.org/10.1136/bmj.322.7300.1447.

25. Kivipelto M, Ngandu T, Laatikainen T, Winblad B, Soininen H, Tuomilehto J. Risk score for the prediction of dementia risk in 20 years among middle aged people: a longitudinal, population-based study. Lancet Neurol. 2006;5: 735-41 https://doi.org/10.1016/S1474-4422(06)70537-3.

26. Knopman DS, Jack CR, Wiste HJ, Weigand SD, Vemuri P, Lowe V, Kantarci K, Gunter UL, Senjem ML, Ivnik RJ, Roberts RO, Boeve BF, Petersen RC. Shortterm clinical outcomes for stages of NIA-AA preclinical Alzheimer disease. Neurology. 2012;78:1576-82 https://doi.org/10.1212/WNL. Ob013e3182563bbe.

27. Koychev I, Lawson J, Chessell T, Mackay C, Gunn R, Sahakian B, Rowe JB, Thomas AJ, Rochester L, Chan D, Tom B, Malhotra P, Ballard C, Chessell I, Ritchie CW, Raymont V, Leroi I, Lengyel I, Murray M, Thomas DL, Gallacher J, Lovestone S. Deep and Frequent Phenotyping study protocol: an observational study in prodromal Alzheimer's disease. BMJ Open. 2019;9:116 https://doi.org/10.1136/bmjopen-2018-024498.

28. Koychev I, Vaci N, Bilgel M, An Y, Muniz GT, Wong DF, Gallacher J, Albert M, Resnick SM, Mogekhar A. Prediction of rapid amyloid and phospotylatedTau accumulation in cognitively healthy individuals; 2020. p. 1-10. https:// doi.org/10.1002/dad2.12019.

29. Lancaster C, Koychev I, Blane J, Chinner A, Chatham C, Taylor K, Hinds C. Gallery game: smartphone-based assessment of long-term memory in adults at risk of Alzheimer's disease. J Clin Exp Neuropsychol. 2020;42:329-43.

30. Luchsinger JA, Reitz C, Honig LS, Tang MX, Shea S, Mayeux R. Aggregation of vascular risk factors and risk of incident Alzheimer disease. Neurology. 2005;65:545-51 https://doi.org/10.1212/01.wnl.0000172914.08967.dc.

31. Merrill DA, Siddarth P, Raji CA, Emerson ND, Rueda F, Ercoli LM, Miller KJ, Lavretsky H, Harris LM, Burggren AC, Bookheimer SY, Barrio JR, Small GW. Modifiable risk factors and brain positron emission tomography measures of amyloid and tau in nondemented adults with memory complaints. Am J Geriatr Psychiatry. 2016;24:729-37 https://doi.org/10.1016/j.jagp.2016.05.007.

32. Mormino E, Betensky R, Hedden T, Schultz A, Amariglio R, Rentz D, Johnson $K$, Sperling R. Synergistic effect of $\beta$-amyloid and neurodegeneration on cognitive decline in clinically normal individuals. JAMA Neurol. 2014;71: 1379-85 https://doi.org/10.1001/jamaneurol.2014.2031.

33. Nakamura A, Kaneko N, Villemagne V, Kato T, Doecke J, Doré V, Fowler C, Li Q, Martins R, Rowe C, Tomita T, Matsuzaki K, Ishii K, Ishii K, Arahata Y,
Iwamoto S, Ito K, Tanaka K, Masters C, Yanagisawa K. High performance plasma amyloid- $\beta$ biomarkers for Alzheimer's disease. Nature. 2018;554:24954 https://doi.org/10.1038/nature25456.

34. Ott A, Stolk RP, van Harskamp F, Pols HA, Hofman A, Breteler MM. Diabetes mellitus and the risk of dementia: the Rotterdam Study. Neurology. 1999;53: 1937-42 https://doi.org/10.1212/wnl.53.9.1937.

35. Palmqvist S, Insel PS, Zetterberg H, Blennow K, Brix B, Stomrud E, Mattsson $\mathrm{N}$, Hansson $\mathrm{O}$. Accurate risk estimation of $\beta$-amyloid positivity to identify prodromal Alzheimer's disease: cross-validation study of practical algorithms. Alzheimers Dement. 2019;15:194-204 https://doi.org/10.1016/j.jalz.2018.08. 014.

36. Pedditizi $E$, Peters $R$, Beckett $N$. The risk of overweight/obesity in mid-life and late life for the development of dementia: a systematic review and meta-analysis of longitudinal studies. Age Ageing. 2016;45:14-21 https://doi. org/10.1093/ageing/afv151.

37. Peila R, Rodriguez BL, Launer $L$. Type 2 diabetes, APOE gene, and the risk for dementia and related pathologies: the Honolulu-Asia Aging Study. Diabetes. 2002;51:1256-62 https://doi.org/10.2337/diabetes.51.4.1256.

38. Podewils LJ, Guallar E, Kuller LH, Fried LP, Lopez OL, Carlson M, Lyketsos CG. Physical activity, APOE genotype, and dementia risk: Findings from the Cardiovascular Health Cognition Study. Am J Epidemiol. 2005;161:639-51 https://doi.org/10.1093/aje/kwi092.

39. Reed B, Ph D, Villeneuve S, Ph D, Mack W, Ph D, Decarli C, Chui HC, Jagust W. Low HDL and high LDL serum cholesterol are associated with cerebral amyloidosis. JAMA Neurol. 2014;71:195-200 https://doi.org/10.1001/ jamaneurol.2013.5390.Low.

40. Ritchie CW, Muniz-Terrera G, Kivipelto M, Solomon A, Tom B, Molinuevo JL, The EPAD Consortium. The European Prevention of Alzheimer's Dementia (EPAD) longitudinal cohort study: baseline data release V500.0. J. Prev. Alzheimer's Dis. 2019;7:1-6 https://doi.org/doi.org/10.14283/jpad.2019.46.

41. Ritchie K, Carrière I, Ritchie CW, Berr C, Artero S, Ancelin ML. Designing prevention programmes to reduce incidence of dementia: prospective cohort study of modifiable risk factors. BMJ. 2010;341:336 https://doi.org/10. 1136/bmj.c3885.

42. Rodrigue KM, Rieck JR, Kennedy KM, Devous MD, Diaz-Arrastia R, Park DC. Risk factors for $\beta$-amyloid deposition in healthy aging: vascular and genetic effects. JAMA Neurol. 2013;70:600-6 https://doi.org/10.1001/jamaneurol. 2013.1342.

43. Rovio S, Kåreholt I, Helkala EL, Viitanen M, Winblad B, Tuomilehto J, Soininen $\mathrm{H}$, Nissinen A, Kivipelto M. Leisure-time physical activity at midlife and the risk of dementia and Alzheimer's disease. Lancet Neurol. 2005;4:705-11 https://doi.org/10.1016/S1474-4422(05)70198-8.

44. Scheltens P, Kuiper M, Ch Wolters E, Barkhof F, Valk J, Weinsten HC, Leys D, Vermersch P, Huglo D, Steinling M. Atrophy of medial temporal lobes on MRI in "probable" Alzheimer's disease and normal ageing: diagnostic value and neuropsychological correlates. J Neurol Neurosurg Psychiatry. 1992;55: 967-72 https://doi.org/10.1136/jnnp.55.10.967.

45. Schneider JA, Arvanitakis Z, Bang W, Bennett DA. Mixed brain pathologies account for most dementia cases in community-dwelling older persons. Neurology. 2007;69:2197-204 https://doi.org/10.1212/01.wnl.0000271090. 28148.24.

46. Solomon A, Kivipelto M, Molinuevo JL, Tom B, Ritchie CW. European Prevention of Alzheimer's Dementia Longitudinal Cohort Study (EPAD LCS): study protocol. BMJ Open. 2018;8:1-12 https://doi.org/10.1136/bmjopen2017-021017.

47. Solomon A, Kivipelto M, Wolozin B, Zhou J, Whitmer RA. Midlife serum cholesterol and increased risk of Alzheimer's and vascular dementia three decades later. Dement Geriatr Cogn Disord. 2009;28:75-80 https://doi.org/ $10.1159 / 000231980$

48. Taylor WD, MacFall JR, Provenzale JM, Paynel ME, McQuoid DR, Steffens DC, Krishnan KRR. Serial MR imaging of volumes of hyperintense white matter lesions in elderly patients: correlation with vascular risk factors. Am J Roentgenol. 2003;181:571-6 https://doi.org/10.2214/ajr.181.2.1810571.

49. Thijssen E, La Joie R, Wolf A, Strom A, Wang P, laccarino L, Bourakova V, Cobigo Y, Heuer H, Spina S, VandeVrede L, Chai X, Proctor N, Airey D, Shcherbinin S, Duggan Evans C, Sims J, Zetterberg H, Blennow K, Karydas A, Teunissen C, Kramer J, Grinberg L, Seeley W, Rosen H, Boeve B, Miller B, Rabinovici G, Dage J, Rojas J, Boxer A, For AR, T. for F.L.D. (ARTFL) I. Diagnostic value of plasma phosphorylated tau181 in Alzheimer's disease and frontotemporal lobar degeneration. Nat Med. 2020;26:387-97 https:// doi.org/10.1038/s41591-020-0762-2. 
50. Weston PSJ, Poole T, Ryan NS, Nair A, Liang Y, Macpherson K, Druyeh R, Malone IB, Ahsan RL, Pemberton H, Klimova J, Mead S, Blennow K, Rossor MN, Schott JM, Zetterberg H, Fox NC. Serum neurofilament light in familial Alzheimer disease. Neurology. 2017;89:2167-75 https://doi.org/10.1212/wnl. 0000000000004667.

51. Wolfson L, Wakefield DB, Moscufo N, Kaplan RF, Hall CB, Schmidt JA, Guttmann CRG, White WB. Rapid buildup of brain white matter hyperintensities over 4 years linked to ambulatory blood pressure, mobility, cognition, and depression in old persons. J Gerontol - Ser A Biol Sci Med Sci. 2013;68:1387-94 https://doi.org/10.1093/gerona/glt072.

\section{Publisher's Note}

Springer Nature remains neutral with regard to jurisdictional claims in published maps and institutional affiliations.

- fast, convenient online submission

- thorough peer review by experienced researchers in your field

- rapid publication on acceptance

- support for research data, including large and complex data types

- gold Open Access which fosters wider collaboration and increased citations

- maximum visibility for your research: over $100 \mathrm{M}$ website views per year

At BMC, research is always in progress.

Learn more biomedcentral.com/submissions 